\title{
PROJETO ACOLHIDA NA COLÔNIA NO ESTADO DE SANTA CATARINA - SC: UM TERRITÓRIO DE IDENTIDADE E TURISMO SOB A ÓTICA DA LINGUAGEM DE PADRÕES
}

\author{
PROJECT ACOLHIDA NA COLÔNIA IN THE STATE OF SANTA CATARINA: A TERRITORY OF IDENTITY \\ AND TOURISM FROM THE STANDPOINT OF LANGUAGE OF STANDARDS
}

\author{
PROYECTO ACOGIDA EN LA COLONIA EN EL ESTADO DE SANTA CATARINA - SC: UN TERRITORIO \\ DE IDENTIDAD Y TURISMO DESDE EL PUNTO DE VISTA DEL LENGUAJE DE PATRONES
}

Marinês da Conceição Walkowski Doutora em Arquitetura e Urbanismo (UFSC) Mestre em Arquitetura e Urbanismo (UFSC) marinesw@gmail.com

Marcia Regina Sartori Damo Doutora em Engenharia Civil (UFSC) Mestre em Engenharia Civil (UFSC) mdamo@hotmail.com

Carlos Loch Doutor em Engenharia Florestal (UFPR) Mestre em Ciências Geodésicas (UFPR) carlos.loch@ufsc.br

Data de Submissão: 14/08/2016 Data de Aprovação: 08/04/2017

\begin{abstract}
RESUMO: O estabelecimento de estratégias e mecanismos de promoção do desenvolvimento econômico e social que concilie os princípios fundamentais da sustentabilidade consiste num desafio contemporâneo para os pesquisadores e gestores públicos das três esferas de governo. A rede de relações sociais são fatores imprescindíveis para a sustentabilidade local, adotando-se práticas endógenas que restaurem o espírito do lugar e o sentimento de pertencimento. O espaço rural brasileiro tem passado por modificações, principalmente nas relações e nas formas de trabalho, possibilitando aos agricultores o aumento da renda familiar por meio de novas atividades, como o turismo, visando à melhoria da qualidade de vida no campo. Exemplo disto é praticado na Associação de Agroturismo Acolhida na Colônia, na Serra Catarinense, a qual objetiva incluir produtivamente localidades rurais, antes excluídas do processo de desenvolvimento e sustentadas em princípios de geração de emprego e renda no meio rural. O objetivo do presente artigo é analisar os princípios da Associação Acolhida na Colônia dentro da ótica da linguagem de padrões adotados pelo pesquisador Christopher Alexander. A metodologia utilizada é a pesquisa exploratória e descritiva. Os principais resultados apontaram para a identificação de princípios que poderão ser incorporados nos planos diretores municipais.
\end{abstract}

PALAVRAS-CHAVE: Turismo; Linguagem de Padrões; Acolhida na Colônia.

ABSTRACT: The establishment of strategies and mechanisms to promote economic and social development that reconcile the fundamental principles of sustainability is a contemporary challenge for researchers and public managers at the three levels of government. The network of social relations is essential for local sustainability adopting endogenous practices that restore the spirit of the place and the feeling of belonging. The Brazilian rural area has undergone changes, mainly in the relations and forms of work, enabling farmers to increase family income through new activities such as tourism, aiming at improving the quality of life in the countryside. An example of this is the Agroturismo Acolhida na Colônia Association, in the mountain region of the state of Santa Catarina, which aims to include rural areas, previously excluded from the development process and based on principles of employment and income generation in rural areas. The purpose of this article is to analyse the principles of the Association, within the language of standards adopted 
by researcher Christopher Alexander. The methodology used is exploratory and descriptive research. The main results pointed to the identification of principles that could be incorporated into the municipal master plans.

KEYWORDS: Tourism; Language of Standards; Acolhida na Colônia.

RESUMEN: El establecimiento de estrategias y mecanismos de promoción del desarrollo económico y social que concilie los principios fundamentales de la sostenibilidad constituye un desafío contemporáneo para los investigadores y gestores públicos de las tres esferas de gobierno. La red de relaciones sociales es un factor imprescindible para la sostenibilidad local, adoptando prácticas endógenas que restauren el espíritu del lugar y el sentimiento de pertenencia. El espacio rural brasileño ha pasado por modificaciones, principalmente en las relaciones y en las formas de trabajo, posibilitando a los agricultores el aumento de los ingresos familiares por medio de nuevas actividades como el turismo, con el objetivo de mejorar la calidad de vida en el campo. Un ejemplo de esto es lo que sucede en la Asociación de Agroturismo Acogida en la Colonia, en la Sierra Catarinense, cuyo objetivo es incluir productivamente las localidades rurales, antes excluidas del proceso de desarrollo y sostenidas en principios de generación de empleo e ingresos en el medio rural. El objetivo del presente artículo es analizar los principios de la Asociación Acogida en la Colonia desde el punto de vista del lenguaje de patrones adoptado por el investigador Christopher Alexander. La metodología utilizada es la investigación exploratoria y descriptiva. Los principales resultados apuntaron hacia la identificación de principios que podrían incorporarse a los planes directores municipales.

PALABRAS CLAVE: Turismo; Lenguaje de Patrones; Acogida en la Colonia.

\section{INTRODUÇÃO}

partir dos anos 80, em função da nova constituição brasileira, que
deu mais autonomia aos Municípios, se desenvolveu no Brasil
uma avassaladora corrida à autonomia das regiões, sub-regiões e da participação da sociedade organizada na busca de alternativas para o seu desenvolvimento sustentável. Em consequência disto, o Governo Estadual de Santa Catarina, bem como as iniciativas regionais capitaneadas por Associações de Municípios, em função desta maior independência como ente federativo, passou a ter, seja em termos administrativos ou e financeiros, contribuições com o surgimento de projetos e planos de desenvolvimento criativos e transformadores, que ao longo do tempo se acumularam e contribuíram decisivamente para transformações na cultura local e regional em diversas regiões do país.

Exemplos disto são o surgimento de consórcios intermunicipais, as experiências em cooperativismo privado, o conceito de mesorregiões, os territórios rurais implementados pelo Governo Estadual e Federal, com identidade cultural, os quais estão sendo fundamentais para o processo de organização dos espaços territoriais.

O estabelecimento de estratégias e mecanismos de promoção do desenvolvimento econômico e social que conciliem os princípios fundamentais 
da sustentabilidade consiste num desafio contemporâneo e relevante para os pesquisadores e gestores públicos das três esferas de governo.

Portanto, são necessárias observações importantes no planejamento regional, especialmente aquelas que podem ter conexões com estratégias de âmbito local e comunitário para que terras agricultáveis, o lixo reciclável, a conservação de energia e água, entre outros, possam ser fonte de geração de emprego e renda para a população.

A criação de parcerias, a mobilidade dos moradores, as práticas de sustentabilidade ambiental relacionadas à produção de energia, água, alimento orgânico, paisagismo produtivo, são instrumentos estratégicos para a promoção do desenvolvimento sustentável que objetive a geração de renda, sem se descuidar da proteção dos recursos ambientais para as gerações futuras.

O espaço rural se destaca pela beleza paisagística e diversidade de potenciais existentes, expressos pela produção do artesanato, agropecuária e pelo próprio patrimônio natural e cultural. O turismo pode auxiliar na geração de renda complementar e na dinamização e na valorização do produto local, melhorando a qualidade do mesmo, incentivando a permanência das famílias de agricultores no campo.

A motivação fundamental para a viagem turística nos destinos naturais é a necessidade de romper com a rotina e a busca pelo convívio com a natureza. A paisagem possibilita esta mudança e oferece ao turista a troca de experiências culturais.

O espaço rural brasileiro tem passado por modificações, principalmente nas relações e nas formas de trabalho. Estas modificações possibilitam aos agricultores o aumento da renda familiar por meio de novas atividades como o turismo, que visa à melhoria da qualidade de vida no campo.

A redução dos limites entre os rurais e urbanos ocorre devido ao meio rural estar aderindo atividades antes comuns aos meios urbanos. Contudo, as desigualdades sociais ainda são bem diferentes, uma vez que o meio rural padece com a falta de condições básicas e de infraestrutura.

O Estado de Santa Catarina, devido sua vocação para a atividade turística, tem investido em novas atividades no espaço rural, que vem crescendo cada 
vez mais por meio de iniciativas de diferentes $O N G$ 's e entidades voltadas ao setor turístico. Tal fato tem despertado o interesse dos municípios em diminuir as desigualdades sociais e buscar novas alternativas de dinamização das atividades agrícolas e não agrícolas.

As estratégias gerais da Associação Acolhida na Colônia, discriminadas no presente artigo, foram introduzidas no território a partir da criação de um Caderno de Normas. Na metodologia de análise, será utilizada a pesquisa exploratória e descritiva. Os dados foram coletados nos Municípios que fazem parte da Associação, a partir de pesquisa documental, observações em campo por um dos autores desta pesquisa, que atua como técnico desde 2011, e observações indiretas em mapas, fotos, dissertações e artigos publicados por outros autores. Os princípios adotados pelo pesquisador Christopher Alexander foram escolhidos com base na realidade dos Municípios que participam da Associação Acolhida na Colônia e possuem condições de ser aprimorados, visando à inserção dos mesmos nos planos diretores municipais. Para tanto, foram construídos quadros demonstrando as estratégias adotadas pela Associação e sua relação com os princípios de sustentabilidade adotados por Christopher Alexander.

\section{O PROCESSO DE DESENVOLVIMENTO REGIONAL EM PROL DE UM DESENVOLVIMENTO SUSTENTÁVEL}

O desenvolvimento regional, atualmente, alicerça-se em diferentes modelos e fatores que geram práticas e dinâmicas distintas. Alguns fatores, como cultura, tradição, crença, arranjos organizacionais, liberdade, capital social e associativismo, quando integrados, tendem a potencializar os ativos endógenos regionais.

Segundo Jordan (2004), quando se instala um processo de desenvolvimento local em determinado território, aparecem sinais que são evidências presentes e que o caracterizam como próprias da sua natureza e o identificam. São elas: Mobilização para a organização e o empoderamento dos atores; articulação para a concentração das instituições; protagonismo dos atores; empreendedorismo, tanto social quanto econômico (com formas de inovação, assunção de riscos e geração de riquezas); endogenia a partir das próprias 
potencialidades do território; perspectiva de expansão regional das ações, superando os limites do território original (formação de consórcios intermunicipais, estabelecimento de redes de cooperação, etc.); e busca e (re) construção da identidade territorial. (JORDAN, 2004, p. 04).

A endogenia surge como reação aos modelos tradicionais de desenvolvimento regional, que tendem a colocar ênfase na atração e na negociação de recursos externos como condição suficiente para a promoção do crescimento econômico das áreas periféricas. O enfoque endógeno visa explorar potenciais e estabelecer o equilíbrio entre fatores internos (endógenos) e os externos (exógenos) do desenvolvimento. Portanto, "endogenia refere-se à capacidade de identificar e promover fatores de desenvolvimento a partir das próprias potencialidades locais, introduzindo iniciativas protagonizadas por organizações sociais de um território" (TURNES, et al., 2004, p. 31).

De acordo com Boisier (1996), a animação dos atores locais e regionais, como função catalisadora do governo regional, adquire maior importância à medida que é reconhecida a sinergia como fundamento do desenvolvimento endógeno e, sobretudo, como base da capacidade local e regional de inovação, peça-chave do desenvolvimento contemporâneo.

O processo de desenvolvimento regional envolve, além das transformações sociais, também um aproveitamento das diferenças regionais, ou seja, as regiões devem aproveitar suas vantagens comparativas e diversificar sua economia baseada nos recursos e nas especificidades de cada região.

Para Becker (2000, p.12), "existem duas condições para que ocorra o desenvolvimento regional: a primeira é a condição econômica, ou seja, uma região (lugar) articulada economicamente, setorializada, verticalizada e hierarquizada pelos interesses econômico-corporativos (reprodução do capital financeiro); a segunda, a região (lugar) social e ambiental, autoarticulada de forma espacializada, regionalizada, horizontalizada e contigualizada pelos interesses regionais (locais de reprodução de vida)".

São muitos os conceitos de desenvolvimento, no entanto, em princípio, todos visam, além da melhoria da renda, à qualidade de vida das populações. Além disso, esse novo enfoque dado ao desenvolvimento voltado para o lugar 
(local) tende a reduzir mais as desigualdades, no momento em que se observa e se age localmente, aproveitando as diferenças e os potenciais de cada região.

Nesse sentido, Barquero (2002), a partir da reflexão sobre a dinâmica dos "sistemas produtivos locais" do sul da Europa, afirma que é necessário e possível que os governos locais tomem iniciativas para enfrentar os problemas internos. O autor acrescenta, ainda, que são necessárias novas estratégias de desenvolvimento que realizem a reestruturação dos sistemas produtivos regionais, desenvolvendo novas cadeias produtivas, aumentando os postos de trabalho e melhorando a qualidade de vida. Isso poderá ser feito através da promoção e/ou expansão da capacidade empresarial e organizativa da economia local, com mobilização de recursos internos e externos.

Também se faz necessário lembrar que hoje se vive num mundo globalizado e, para que a região possa participar do mercado cada dia mais exigente, deverá desenvolver seus potenciais regionais, buscando desenvolver sua economia com base em suas vantagens comparativas, mas também valorizando seus indivíduos, tornando-os mais informados, qualificando-os, melhorando, assim, seu bem-estar.

O primeiro desafio para o desenvolvimento é considerar os determinantes históricos, sociais, políticos, econômicos e institucionais que permeiam as relações sociais locais de um território. Da mesma forma, é preciso estar atento às relações entre o poder local e a sociedade civil quando se quer obter cooperação, gestão compartilhada e participação do cidadão nas questões públicas.

Contudo, entende-se que toda a população deve ser chamada a participar de forma representativa, mesmo que, para isso, ela necessite ser capacitada para discutir os interesses comuns do seu território e identificar sua estrutura social e econômica para buscar soluções de forma consensual.

No caso do desenvolvimento regional, todos os atores sociais, sejam públicos ou privados, são elementos importantes para se trabalhar qualquer modelo de desenvolvimento, já que o planejamento participativo poderá propiciar e garantir a representatividade dos atores a partir da diversidade de interesses. Essa participação assumirá um papel determinante na orientação 
das políticas públicas da região e transformará as relações entre os cidadãos e o governo local.

A sustentabilidade do desenvolvimento depende tanto do modo de conduzir as iniciativas, como dos valores e princípios das propostas de desenvolvimento. O próprio Estado, muitas vezes, inviabiliza processos que conquistaram a motivação e o compromisso da sociedade local em função da sua estrutura burocrática. Entretanto, os processos sociais com sustentabilidade são aqueles que rejeitam as ações compensatórias ou pontuais, por melhores que sejam as intenções dos dirigentes.

Em síntese, o desenvolvimento regional é um processo que significa construir comportamentos embasados na cooperação, no pluralismo político e na solidariedade, a partir de estratégias voltadas para a construção de capacidades, enriquecimento com valores e comportamentos voltados para o desenvolvimento sustentável.

\section{O TURISMO NO ESPAÇO RURAL E O AGROTURISMO}

O turismo é uma atividade que vem evoluindo nos últimos anos, servindo de alternativa para o desenvolvimento econômico em muitos locais.

Para compreender melhor esta atividade, uma das definições é dada pela Organização Mundial do Turismo (2003, p.20), em que o turismo compreende "as atividades de pessoas que viajam para lugares afastados de seu ambiente usual, ou que neles permaneçam por menos de um ano consecutivo, a lazer, a negócio ou por outros motivos".

A evolução da atividade turística, bem como o surgimento de novas necessidades por parte dos viajantes, tem possibilitado a abertura de fronteiras e o fortalecimento da atividade, gerando renda aos destinos visitados.

Devido ao aumento de demanda turística por ambientes naturais, o espaço rural vem se destacando por meio de diferentes segmentos, como o turismo rural e o agroturismo. O componente principal é a propriedade do homem do campo e sua família com destinação ao acolhimento do turista e a busca do natural e da simplicidade. 
Para o Ministério do Turismo (2005), o Turismo Rural, ou Agroturismo, é definido como um conjunto de atividades desenvolvidas, comprometidas com a produção agropecuária, agregando valor a produtos e serviços, resgatando e promovendo o patrimônio natural e cultural das populações rurais.

O turismo no espaço rural se destaca pelo desenvolvimento de diferentes segmentos (turismo rural, agroturismo, entre outros), e propicia o contato direto entre pessoas e a busca pelo valor da natureza. Esta atividade vem sendo respaldada pela atual Política Nacional de Turismo por meio do Programa de Regionalização do Turismo, que visa regionalizar territórios e produtos turísticos onde ocorre a interação do homem com os ambientes, dando origem a diversas formas de organizações sociais e de relações sociedade e natureza (CORIOLANO, 2009).

Santos (2004) define o espaço como um conjunto indissociável, solidário e também contraditório de sistemas de objetos e sistema de ações, não considerados isoladamente, mas como quadro único no qual a história se dá. Este conjunto de sistemas permite entender as formas representativas de relações sociais passadas e do presente e que estão acontecendo diante dos nossos olhos e se manifestam através de processos e funções. As modificações são reflexos de novas ações e acabam por criar novos objetos, transformando as relações no espaço.

Em relação ao turismo, este espaço se torna ainda mais dinâmico e sofre novas modificações para atender a demanda. O espaço turístico é consequência da presença e distribuição territorial dos atrativos turísticos que, não devemos esquecer, são a matéria-prima do turismo. Este elemento do patrimônio turístico, mais o empreendimento e a infraestrutura turística, são suficientes para definir o espaço turístico de qualquer país. (BOULLÓN, 2002, p. 79).

O espaço é adaptado para a atividade turística cujas práticas usufruem dos atrativos e dispõem de elementos como a infraestrutura para atrair mais visitantes a um destino, além das relações com os prestadores de serviços diretos e indiretos. O turismo usufrui das condições sociais existentes e a atratividade varia em relação ao patrimônio natural e cultural e a própria convivência com o cotidiano agrícola. 
O Brasil rural comporta uma multiplicidade de ambientes físicos, recursos naturais, agroecossitemas, sistemas agrários, etnias, culturas sociais, padrões tecnológicos, formas de organização social e política, linguagens, simbologias, demonstrando que o espaço rural brasileiro não é uniforme, mas diverso, plural e heterogêneo (MDA, 2006).

A agricultura familiar vem enfrentando dificuldades na geração de renda. Entre as principais causas, estão a falta de emprego e o aumento da produtividade industrial, dificultando a participação dos pequenos agricultores familiares nos mercados competitivos. Como consequência, muitos habitantes abandonam estes municípios em busca de condições mais dignas de vida. O êxodo rural favorece o empobrecimento das famílias e ocasiona problemas socioculturais como o desordenamento urbano, além de baixa estima destas famílias.

Surge a necessidade de dinamizar as atividades no campo na tentativa de resgatar a autoestima do agricultore revitalizar o espaço rural. As novas atividades não agrícolas, também chamadas de agricultura pluriativa, são uma forma de incrementar a renda familiar. Um exemplo é o Agroturismo (segmento adotado pelo projeto Acolhida na Colônia), que possibilita a troca de experiências e o convívio com os hábitos das famílias rurais, gerando renda complementar a partir de atividades não agrícolas como o turismo.

\section{A PLURIATIVIDADE E A MULTIFUNCIONALIDADE COMO ALTERNATIVA PARA A AGRICULTURA FAMILIAR}

A pluriatividade é um processo de mudança que ocorreu nas relações de trabalho e sua discussão teve início nos anos 70 na Europa. Desde então, a produção agrícola tem passado por transformações, diversificando cada vez mais as atividades econômicas no espaço rural.

Schneider (2003) definiu a pluriatividade como um fenômeno através do qual membros das famílias de agricultores que habitam o meio rural opta pelo exercício de diferentes atividades, ou mais rigorosamente, optam pelo exercício de atividades não agrícolas, mantendo a moradia no campo e uma ligação, inclusive produtiva, com a agricultura e a vida no espaço rural. 
O turismo também é visto como atividade não agrícola e tem possibilitado uma nova dinâmica com a vinda de visitantes aos municípios rurais, dando a oportunidade para os agricultores explorarem suas propriedades (unidade familiar) por meio de novas atividades que não somente a agricultura e a pecuária, mas também a prestação de serviços.

Mais do que uma estratégia de reprodução dos agricultores familiares, a pluriatividade surgiu como uma necessidade de reestruturação no campo que se manifestou por três razões (SCHNEIDER, 2003):

a) em função da emergência de atividades não agrícolas, principalmente pelo transbordamento das cidades e do mercado de trabalho urbano por áreas rurais, e da interiorização de determinados tipos de indústria;

b) pela crise do setor agrícola exportador no início da década de 1990, que acarretou aqueda da rentabilidade dos principais produtos daagropecuária brasileira e a queda das rendas agrícolas especialmente dos agricultores familiares;

c) em função do limite de crescimento do emprego agrícola diante da alta taxa de ociosidade tecnológica e do subemprego vigente na estrutura agrária brasileira.

No Brasil, desde a década de 90, os conceitos de tempo parcial e a pluriatividade tornaram-se foco de estudos e são apresentadas pelo Projeto Rurbano em 1995.

No mundo rural dos países desenvolvidos, esse novo paradigma "pósindustrial" tem um ator social já consolidado: o part-time farmer que se pode traduzir por agricultores em tempo parcial. A sua característica fundamental é que ele não é mais somente um agricultor ou um pecuarista, e sim um agricultor que combina atividades agropecuárias com outras atividades não agrícolas, dentro ou fora de seu estabelecimento, tanto nos ramos tradicionais urbanoindustriais como nas novas atividades que vêm se desenvolvendo no meio rural, como lazer, turismo, conservação da natureza, moradia e prestação de serviços pessoais (SILVA, 2001). 
Está iniciativa visa diminuir a pobreza e dinamizar o espaço rural, por meio da captação de renda, ou seja, diferentes atividades vinculadas aos segmentos de turismo.

Para Gomez-Limon et al. (2012), o conceito de multifuncionalidade surgiu na União Europeia no final do século passado (1998/1999), para se referir à vasta gama de produtos e serviços que o setor agrícola fornece à sociedade.

No Brasil, a primeira menção ao termo multifuncionalidade na agricultura e do território ocorreu durante a ECO-92, no Rio de Janeiro, e revelou uma preocupação com um rural não exclusivamente agrícola e com os significados não exclusivamente produtivos da prática agrícola. Por isso, é possível dizer que a noção de multifinalidade da agricultura surge como uma nova visão que integra a agricultura a projetos de desenvolvimento no contexto de busca de soluções para as "disfunções" do modelo produtivista e inova ao induzir uma visão integradora das esferas sociais na análise do papel da agricultura e da participação das famílias no desenvolvimento local (CARNEIRO, 2002). A noção de multifuncionalidade vem ao encontro das modificações ocorridas no espaço e a expansão das práticas por meio da manutenção e da preservação dos recursos naturais e culturais presentes na paisagem rural. Essa nova visão integra a agricultura a projetos de desenvolvimento local, respeitando, assim, a diversidade das realidades locais, o que leva ao questionamento da exclusividade do modelo produtivista.

Entende-se que, dentro dessas novas funções, o rural se torna mais amplo que o agrícola. As atividades não agrícolas integradas à agricultura passam a valorizar as relações de trabalho, envolvendo os agricultores familiares e oferecendo diferentes opções de trabalho por meio da pluriatividade. Já a multifuncionalidade tem possibilitado repensar o papel do espaço vinculado à valorização do patrimônio natural e cultural. As novas funções do espaço rural também contribuem para o surgimento de diferentes segmentos para o turismo.

As discussões referentes ao surgimento de novas atividades no campo se tornam relevantes à medida que interferem nas políticas de desenvolvimento agrário, bem como no planejamento das atividades turísticas, levando em consideração a vocação de cada território. 
Um processo de desenvolvimento local pressupõe o envolvimento da população de um determinado território. A criação de "estados de mobilização" orientados para a transformação da realidade é a primeira condição para que as mudanças que advirão sejam sustentáveis (política, social e ambientalmente) (PAULILO; SCHMIDT, 2003).

Dentre as iniciativas recentes que se destacaram como alternativa de dinamização do espaço rural no cenário estadual está o município de Santa Rosa de Lima, que vem desenvolvendo atividades não agrícolas a partir de seu envolvimento, desde 1996, com a criação da Associação de Agroturismo Acolhida na Colônia da Serra Catarinense (AAAC).

\section{OS PRINCÍPIOS DE SUSTENTABILIDADE}

O conceito de sustentabilidade se consolidou no final do século XX e está relacionado à evolução da consciência mundial com o meio ambiente. Neste aspecto, a realização da Conferência das Nações Unidas para o Meio Ambiente Humano, realizada em 1972, é um dos marcos iniciais. Na continuidade, a Comissão Mundial sobre o Meio Ambiente e o Desenvolvimento (CMMAD) produziu um documento denominado "Nosso Futuro Comum", divulgado em 1987, em que a expressão desenvolvimento sustentável foi largamente utilizada, mostrando a preocupação com as atuais e futuras gerações (DIAS, 2003).

Segundo o mesmo autor, o documento Nosso Futuro Comum foi referência e base dos debates quando da realização da Conferência das Nações Unidas sobre o meio ambiente e o Desenvolvimento (CNUMAD), realizada no Rio de Janeiro em 1992 (ECO 92), que popularizou e consolidou a utilização do conceito de desenvolvimento sustentável (DIAS, 2003).

Neste sentido, a partir da década de 90, até motivados pela realização da Rio 1992 e a construção da Agenda 21, os conceitos e os princípios de sustentabilidade foram gradativamente sendo incorporados por regiões, conjunto de municípios, organizações não governamentais e sociedade civil em geral.

Contudo, há críticas a este relatório, à medida que os problemas sociais e ambientais são considerados apenas desvios do modelo de desenvolvimento 
sustentável e observa-se uma contradição entre os termos "desenvolvimento" e "sustentabilidade", devido ao fato de que o primeiro está vinculado à produção de mercadorias; e o segundo ressalta a manutenção das condições, considerado inviável na produção de novas e contínuas mercadorias (RODRIGUES, 2002).

De acordo com Sachs (1993), as dimensões da sustentabilidade são as seguintes:

a) sustentabilidade social: é a criação de um processo de desenvolvimento civilizatório baseado no ser e que seja sustentado por uma maior equidade na distribuição do ter, nos direitos e nas condições das amplas massas da população, e achatar a distância entre os padrões de vida dos mais ricos e mais pobres;

b) sustentabilidade econômica: possibilita uma melhor alocação e gestão mais eficiente dos recursos e por um fluxo regular do investimento público e privado. Esta eficiência é macrossocial, reduzindo os custos sociais e ambientais, bem diferente da lógica economicista;

c) sustentabilidade ecológica: incrementa o aumento da capacidade de recursos naturais, limitando os recursos não renováveis ou ambientalmente prejudiciais, reduzindo o volume de poluição, autolimitando o consumo material pelas camadas sociais mais privilegiadas, intensificando a pesquisa de tecnologias limpas e definindo regras para uma adequada proteção ambiental;

d) sustentabilidade espacial: é aquela voltada a uma configuração ruralurbana mais equilibrada com ênfase nas seguintes questões: diminuição da concentração excessiva nas áreas urbanas e dos processos de colonização descontrolados, promoção de projetos modernos de agricultura regenerativa e agroflorestamento, industrialização centralizada, criação de empregos rurais não agrícolas, e o estabelecimento de uma rede de reservas naturais e de biosfera para proteger a biodiversidade;

e) sustentabilidade cultural: engloba as raízes endógenas dos modelos de modernização e dos sistemas rurais integrados de produção, respeitando a continuidade das tradições culturais, e até mesmo a pluralidade das soluções particulares;

f) sustentabilidade política: privilegia a negociação da diversidade de interesses movidos em questões fundamentais desde o âmbito local ao global. 
O mesmo autor introduziu mais quatro dimensões de sustentabilidade: ambiental, territorial, política nacional e política internacional.

A dimensão da sustentabilidade ambiental possibilita aos ecossistemas naturais realizarem autodepuração. A dimensão territorial busca eliminar as desigualdades entre o meio urbano e rural, buscando a melhoria do ambiente urbano, a superação das disparidades inter-regionais e as estratégias de desenvolvimento ambiental, voltada aos ambientes frágeis. A dimensão da política nacional visa alcançar a democracia por meio da apropriação universal dos direitos humanos, o desenvolvimento da capacidade do Estado para implementar o projeto nacional em parceria com outros empreendimentos e a busca de um nível razoável de coesão social. Já a dimensão da política internacional busca garantir a paz e a cooperação internacional, por meio do fortalecimento da ONU, um pacote Norte-Sul de co-desenvolvimento, baseado no princípio de igualdade, um controle institucional efetivo do sistema internacional financeiro e de negócios, da aplicação do princípio da precaução na gestão do meio ambiente e dos recursos naturais, bem como da proteção da biodiversidade biológica, gestão do patrimônio global e cooperação científica e tecnológica (SACHS, 2000).

Combasenestesmovimentos, embora ainda contraditórios, a sustentabilidade passou ser integrada às mais diversas áreas, incluindo o turismo.

Uma das estratégias conectadas com princípios e dimensões da sustentabilidade deve necessariamente promover a qualidade de vida e a preservação ambiental, através de ações que enfatizem modelos locais com tecnologias apropriadas, em particular para as zonas rurais, como é o caso do projeto Acolhido na Colônia aqui em análise.

\section{O PROJETO ACOLHIDA NA COLÔNIA - UM TERRITÓRIO DE IDENTIDADE}

O setor de serviços associados ao turismo começou a se destacar e a ganhar espaço no cenário nacional, pela diversidade brasileira, como oportunidade 
de geração de inúmeros empregos e renda, ao mesmo tempo, preservando, incluindo e reduzindo as graves desigualdades inter e intrarregionais, ainda muito presentes em nível de Brasil.

O projeto denominado Acolhida na Colônia adota princípios de sustentabilidade, por meio do agroturismo, da inclusão social, da geração de renda, da construção de rede social dentro de um território de identidade.

Localizada na região sudeste de SC a $150 \mathrm{~km}$ de Florianópolis, a região das Encostas da Serra Geral é um corredor ecológico entre o Parque Nacional de São Joaquim e o Parque Estadual da Serra do Tabuleiro.

Duas vocações polarizam os atores locais no debate sobre desenvolvimento sustentável dos espaços rurais da região, sendo eles: o reflorestamento e a produção orgânica, combinada com outras estratégias de agregação de valor, como agroturismo, ecoturismo, turismo de aventura, entre outros, com opções para a pequena propriedade (unidade familiar). Segundo Cabral (2004), o espaço ocupado pelo território das Encostas da Serra teve sua estrutura fundiária baseada em pequenas propriedades, que geraram a atual organização baseada na produção familiar. Estas estruturas, em função de mudanças no contexto sociopolítico e econômico, especialmente a partir de 1980, produziram demandas que acabaram resultando em um projeto de desenvolvimento territorial e uma rede cooperada de organizações. Tal fato foi impulsionado pelos movimentos migratórios ocorridos na década de 90, de agricultores para centros urbanos do litoral catarinense, em função da crise da economia do porco macau ${ }^{1}$, a queda dos preços do fumo - atividade que sucedeu a anterior como geradora de renda - gerou problemas e muito desestímulo.

Neste contexto, o projeto Acolhida na Colônia surgiu no Brasil em 1996, a partir de um movimento coordenado pela Associação dos Agricultores Ecológicos das Encostas da Serra Geral (AGRECO), em função da resistência dos agricultores familiares que desejavam permanecer em suas terras, apoiados por um grupo de técnicos comprometidos com o desenvolvimento sustentável, tendo como princípio o respeito ao meio ambiente. É uma associação de agricultores integrada à Rede Accueil Paysan (atuante na França desde 1987), que tem a 1 Espécie de suíno, produzido na região. 
proposta de valorizar o modo de vida no campo por meio do Agroturismo Ecológico (GUZZATTI, 2010).

Em 2008, a Associação Acolhida na Colônia conquistou o título de Destino Referência no Segmento Turismo Rural, segundo o Plano Nacional de Turismo 2007/2010 (MTur, 2011), a partir de um arranjo constituído pelos quatro municípios: Santa Rosa de Lima, Anitápolis, Rancho Queimado e Urubici. Tal reconhecimento tem trazido benefícios importantes, especialmente à divulgação do destino.

Os municípios de Anitápolis, Santa Rosa de Lima e Rancho Queimado se localizam entre as regiões nomeadas de Serras do Leste Catarinense (Complexo Serra do Tabuleiro) e Encostas da Serra Geral, e o município de Urubici no Planalto Catarinense (Figura 01).
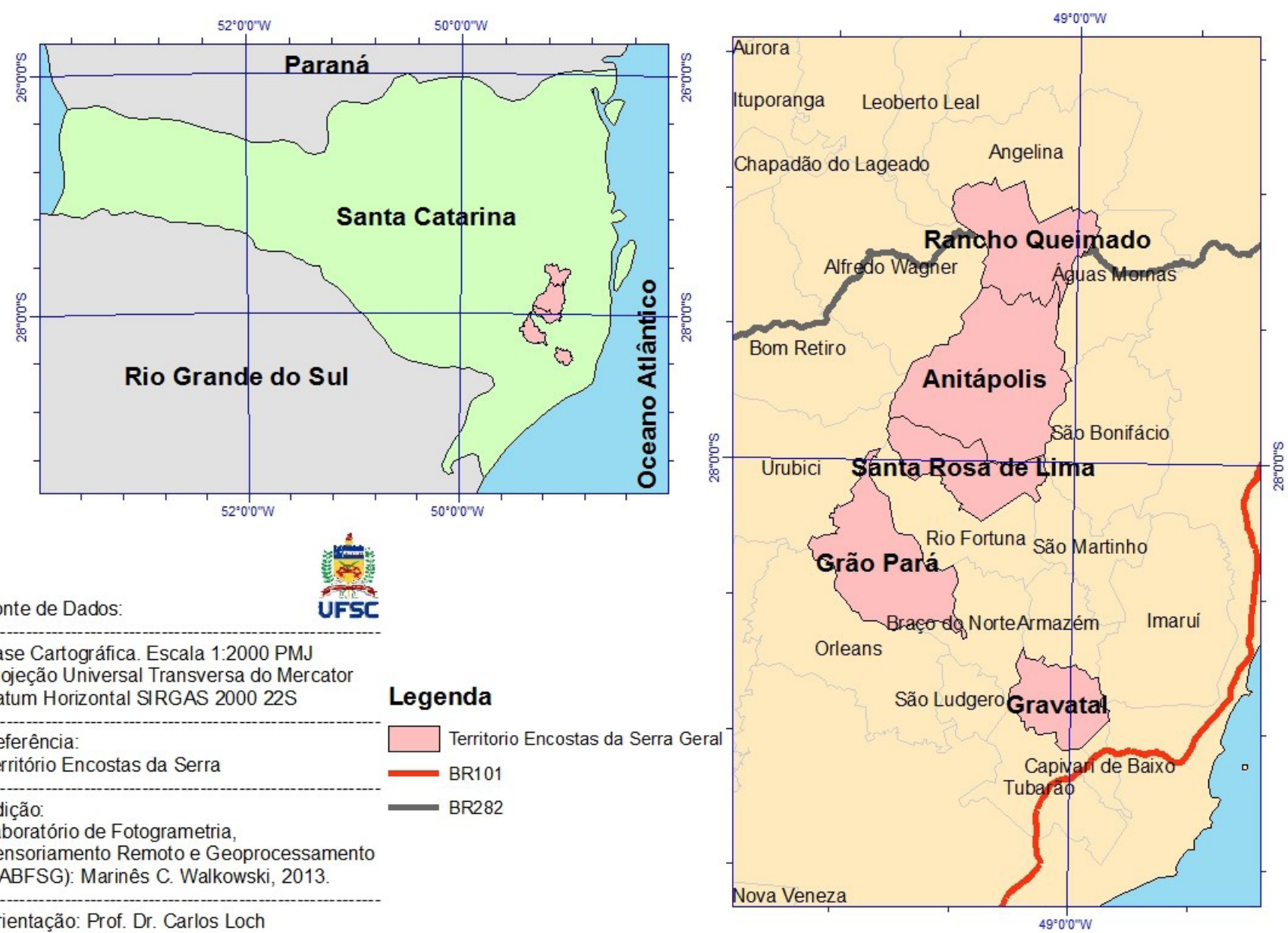

Figura 01: Território Encostas da Serra Geral.

Fonte: Walkowski, 2013.

Em 2009, foi constituída a Associação dos Municípios das Encostas da Serra Geral, indicando a importância dessa região e o potencial para a construção do território. 
A região é composta por municípios essencialmente rurais, com predomínio de unidades familiares de produção. A Associação de Agroturismo Acolhida na Colônia vem atuando no estado de Santa Catarina desde 1999 e conta atualmente com aproximadamente cento e setenta famílias de agricultores, distribuídos em 27 municípios. Faz parte da rede internacional de agroturismo Accueil Paysan, hoje presente em 40 países de quatro continentes, sendo que na América Latina a primeira experiência implementada é a da Acolhida na Colônia. Vale salientar que a Associação, no Brasil, é considerada a segunda maior filial e a mais organizada (GUZZATTI, 2010).

Em relação à atual divisão territorial da administração pública estadual, Rancho Queimado e Anitápolis pertencem à Secretaria de Desenvolvimento Regional (SDR) da Grande Florianópolis, enquanto Santa Rosa de Lima pertence à SDR de Braço do Norte e Urubici pertence à SDR de São Joaquim, como demonstrado na Figura 01.

Atualmente, a associação está localizada em 6 (seis) territórios das Secretarias Regionais de Desenvolvimento, região administrativa e de desenvolvimento, instituídas pelo governo de Santa Catarina, em 2003, o qual objetiva regionalizar o desenvolvimento, descentralizar as ações de governo e desconcentrar o poder.

A região com maior número de municípios envolvidos no projeto é a Encosta da Serra Geral, composta pelos municípios: Rancho Queimado, Anitápolis, Santa Rosa de Lima, Grão-Pará e Gravatal.

A Associação também foi ampliada por meio de um projeto de expansão em: Aurora, Atalanta, Agronômica, Agrolândia, Vitor Meirelles, Witmarsum, Presidente Getulio, Lontras e Presidente Nereu, com base em recursos do Ministério do Desenvolvimento Agrário (AAAC, 2013).

Esta iniciativa tem sido pioneira no Estado de Santa Catarina e pode ser considerada um exemplo de turismo solidário, à medida que envolve a população, desde o início do processo e oferece a oportunidade de geração de renda aos jovens e adultos.

Em cada uma destas propriedades (unidade familiar) são trabalhados diferentes tipos de serviços, focando na complementariedade entre os mesmos: alimentação, hospedagem, venda de produtos e atividades de lazer. 
Ainda, muitas famílias de agricultores têm sido favorecidas por meio de recursos oriundos de iniciativas públicas e privadas. A constituição de uma associação pode elevar a qualidade de vida, servindo de exemplo para que outros municípios se mobilizem, adequando suas atividades agrícolas e não agrícolas às práticas mais saudáveis de vida, por meio de produção orgânica, além de gerar renda com a vinda de visitantes.

\section{METODOLOGIA E ANÁLISE: A LINGUAGEM DE PADRÕES DE}

CHRISTOPHER ALEXANDER

O estudo, o aprimoramento de práticas já adotadas e a implementação de padrões adotados por Alexander et al. (1977) na presente estratégia de desenvolvimento adotada pela Associação Acolhida na Colônia poderão potencializar ainda mais os importantes resultados para a inserção da população rural no processo de desenvolvimento regional, através da inclusão produtiva, com princípios de sustentabilidade bem trabalhados.

Conforme Lynch (2007) e Sattler (2007), a obra de Alexander et al. (1977), denominada "Uma Linguagem de Padrões". se apresenta como uma fonte rica de conhecimentos acerca de como fazer bons lugares. E fazer um bom lugar é princípio fundamental para a região de abrangência da Acolhida na Colônia, por meio do turismo e da inserção do mercado da produção orgânica.

Christopher Alexander é considerado um dos pioneiros a tratar da importância do ambiente espacial, no seu conjunto, e acerca das razões que o tornam bom (LYNCH, 2007). Alexander, através de sua obra "Uma Linguagem de Padrões", reconhece que há um extenso e criterioso trabalho de análise e observação de lugares bem-sucedidos, busca identificar padrões urbanos, do ambiente físico, recorrentes nesses lugares, que, independente da época, conferem qualidade espacial aos assentamentos humanos. Dessa forma, propõe padrões (patterns), resgata uma série de qualidades 'renegadas, esquecidas, abandonadas' pelo modernismo e que podem, hoje, contribuir para a solução de questões colocadas pela sustentabilidade. Sua obra ainda visa relacionar padrões de forma sistêmica, compreendendo que para solução do problema é necessária uma visão holística (LYNCH, 2007; SATTLER, 2007, MOEHLECKE, 2010). 
Sattler (2007) observa que a obra de Christopher Alexander e sua equipe é rica em padrões embasadores de propostas de sustentabilidade. E foi em consequência disto que a Associação Acolhida na Colônia se tornou um bom estudo de caso. Neste sentido foram selecionados alguns padrões que já são adotados pelo Projeto Acolhida na Colônia e que possuem condições de um aprimoramento para um melhor resultado (Quadro 1). Também foram relacionados aqueles padrões recomendados e que devem fazer parte dos instrumentos inseridos nos planos diretores municipais (Quadro 2). Os quadros são compostos de quatro colunas que tratam do problema/contexto onde são caracterizados os padrões adotadas; as recomendações de como esses padrões deverão ser inseridos no projeto; a sua relação com os princípios já adotados pelo projeto; e a situação do projeto Acolhida na Colônia.

QUADRO 1 - PADRÕES JÁ UTILIZADOS PELO PROJETO ACOLHIDA NA COLÔNIA

\begin{tabular}{|c|c|c|c|c|}
\hline \multicolumn{5}{|c|}{ 1. INTERPENETRAÇÃO CAMPO-CIDADE** (city country fingers) } \\
\hline $\begin{array}{l}\text { Problema/Contexto } \\
\text { (Padrão) }\end{array}$ & Recomendações & & Relações & $\begin{array}{c}\text { Projeto Acolhida na } \\
\text { Colônia }\end{array}$ \\
\hline $\begin{array}{l}\text { Urbanização desordenada } \\
\text { torna as cidades } \\
\text { insuportáveis e causa } \\
\text { mal-estar na população } \\
\text { pela falta de contato com } \\
\text { o campo. }\end{array}$ & $\begin{array}{c}\text { Entrelaçar faixas de } \\
\text { solo urbano e rural } \\
\text { como } \\
\text { estratégias de } \\
\text { desenvolvimento }\end{array}$ & & $\begin{array}{l}\text { Equilíbrio - área } \\
\text { cupada e área livre } \\
\text { erção de áreas verdes } \\
\text { em centros urbanos } \\
\text { ntribuir para questões } \\
\text { de habitabilidade } \\
\text { Produção local de } \\
\text { alimentos. }\end{array}$ & $\begin{array}{l}\text { Desenvolve estratégias } \\
\text { de comercialização e } \\
\text { divulgação para atrair } \\
\text { turistas dos meios urbanos } \\
\text { como fuga dos grandes } \\
\text { centros e do stress diário. } \\
\text { Promove ambiente } \\
\text { aconchegante e contato } \\
\text { com a flora e a fauna } \\
\text { para atrair adeptos ao } \\
\text { segmento de turismo no } \\
\text { espaço rural. }\end{array}$ \\
\hline \multicolumn{5}{|c|}{ 2. VALES AGRÍCOLAS* (agricultural valleys) } \\
\hline $\begin{array}{l}\text { Problema/Contexto } \\
\text { (Padrão) }\end{array}$ & Recomendações & & Relações & $\begin{array}{l}\text { Projeto Acolhida na } \\
\text { Colônia }\end{array}$ \\
\hline $\begin{array}{l}\text { A melhor terra para a } \\
\text { agricultura costuma ser } \\
\text { também a melhor para } \\
\text { a moradia, porém a } \\
\text { quantidade é limitada. }\end{array}$ & $\begin{array}{l}\text { Preservar os vales agríc } \\
\text { como terra de cultiv } \\
\text { proteger estes terreno } \\
\text { qualquer urbanização, } \\
\text { destrua ou ponha em } \\
\text { a fertilidade do solc } \\
\text { Inibir a implantaçãc } \\
\text { de condomínios de } \\
\text { alto padrão, que } \\
\text { pouco contribui com } \\
\text { desenvolvimento loc }\end{array}$ & $\begin{array}{l}\text { olas } \\
\text { e } \\
\text { de } \\
\text { que } \\
\text { isco } \\
\\
\text { o } \\
\text { al. }\end{array}$ & $\begin{array}{l}\text { Preservação de } \\
\text { áreas cultiváveis } \\
\text { e necessidade } \\
\text { de conter a } \\
\text { urbanização sobre } \\
\text { estas. } \\
\text { Equilíbrio na } \\
\text { ocupação de áreas } \\
\text { menos propícias à } \\
\text { produção agrícola. }\end{array}$ & $\begin{array}{l}\text { Apoia princípios do } \\
\text { agroturismo e do } \\
\text { associativismo, os } \\
\text { quais visam auxiliar a } \\
\text { permanência do agricultor } \\
\text { no campo. }\end{array}$ \\
\hline
\end{tabular}


DoI: 10.14210/rtva.v18n2.p319-347

\begin{tabular}{|c|c|c|c|c|}
\hline \multicolumn{5}{|c|}{ 3. CIDADES RURAIS* (country towns) } \\
\hline $\begin{array}{l}\text { Problema/Contexto } \\
\text { (Padrão) }\end{array}$ & Recomendações & Relações & \multicolumn{2}{|c|}{ Projeto Acolhida na Colônia } \\
\hline $\begin{array}{l}\text { A cidade grande é um } \\
\text { ímã atrativo de pessoas, } \\
\text { causando migração } \\
\text { massiva em direção } \\
\text { às cidades, em busca } \\
\text { não só de trabalho, } \\
\text { mas também em busca } \\
\text { de possibilidades de } \\
\text { informação, lazer, cultura, } \\
\text { entre outros. }\end{array}$ & $\begin{array}{l}\text { Incentivar formas de } \\
\text { manter as pessoas em seus } \\
\text { lugares, com atividades } \\
\text { industriais/comerciais } \\
\text { locais, de modo que } \\
\text { estas cidades não sejam } \\
\text { dormitórios, para as } \\
\text { pessoas que trabalham em } \\
\text { outros lugares. }\end{array}$ & $\begin{array}{l}\text { Incentivo ao } \\
\text { desenvolvi- } \\
\text { mento } \\
\text { econômico } \\
\text { local. }\end{array}$ & \multicolumn{2}{|c|}{$\begin{array}{c}\text { Apoia o desenvolvimento } \\
\text { regional integrado capitaneado } \\
\text { pelo conjunto de municípios } \\
\text { que integram a grande } \\
\text { Florianópolis. } \\
\text { Busca alternativas de } \\
\text { desenvolvimento que tenham } \\
\text { a endogenia como ponto } \\
\text { fundamental, valorizando } \\
\text { as características da região. } \\
\text { Incentiva famílias a se manter } \\
\text { por meio da criação de } \\
\text { agroindústrias dos mais variados } \\
\text { produtos (cachaça, compotas, } \\
\text { mel, embutidos em geral). } \\
\text { Contribui com a geração } \\
\text { de empregos para os filhos } \\
\text { de agricultores que acabam } \\
\text { assumindo algumas atividades } \\
\text { como guias locais em trilhas, } \\
\text { cachoeiras, cavalgadas } \\
\text { e por meio da venda do } \\
\text { artesanato. Apoia o Centro de } \\
\text { Desenvolvimento do Jovem } \\
\text { Rural (Cedejor), que atua com } \\
\text { foco na permanência do jovem } \\
\text { no espaço rural e na geração de } \\
\text { oportunidades no campo. }\end{array}$} \\
\hline \multicolumn{5}{|c|}{ 4. HORTA* (vegetable garden) } \\
\hline $\begin{array}{c}\text { Problema/Contexto } \\
\text { (Padrão) }\end{array}$ & Recomendações & Relações & & $\begin{array}{c}\text { Projeto Acolhida na } \\
\text { Colônia }\end{array}$ \\
\hline $\begin{array}{l}\text { Numa cidade saudável, } \\
\text { cada família pode cultivar } \\
\text { as verduras necessárias } \\
\text { para seu sustento. Explica } \\
\text { serem os legumes e as } \\
\text { verduras os alimentos } \\
\text { mais básicos. São os } \\
\text { únicos capazes de } \\
\text { sustentar, sozinhos, a } \\
\text { vida humana; em um } \\
\text { mundo ecologicamente } \\
\text { equilibrado, o homem } \\
\text { tem que alcançar uma } \\
\text { relação equilibrada com } \\
\text { sua alimentação diária. }\end{array}$ & $\begin{array}{c}\text { Recomenda que se reserve } \\
\text { um pedaço de terra, em } \\
\text { cada jardim particular ou } \\
\text { em terrenos comunitários, } \\
\text { para serem destinados à } \\
\text { horta. }\end{array}$ & $\begin{array}{r}\text { Importânc } \\
\text { do caráter } \\
\text { dos jardin } \\
\text { do paisagis } \\
\text { produtivo, ta } \\
\text { público, co } \\
\text { privados. Con } \\
\text { com estratégia } \\
\text { reservar esp } \\
\text { para produ } \\
\text { de aliment } \\
\text { que atenda } \\
\text { às demand } \\
\text { familiares; ai } \\
\text { para a troca } \\
\text { alimentos eı } \\
\text { vizinhos. Po } \\
\text { contribuir } p \\
\text { estreitar laço } \\
\text { relacionamen } \\
\text { vizinhanç }\end{array}$ & \begin{tabular}{l|} 
a \\
til \\
no \\
nto \\
no \\
ribui \\
para \\
ços \\
ão \\
s, \\
m \\
as \\
dda \\
de \\
tre \\
de \\
ara \\
de \\
o na \\
.
\end{tabular} & \begin{tabular}{|} 
Este princípio é \\
amplamente trabalhado \\
nas capacitações e no \\
caderno de normas, em \\
que cada família busca \\
diversificar sua produção \\
e estabelecer parcerias \\
com outras famílias por \\
meio da troca e compra \\
de produtos. Esta iniciativa \\
possibilita que muitas \\
famílias escoem seus \\
produtos diretamente ao \\
turista ou no município. \\
O projeto de paisagismo \\
nas propriedades (unidade \\
familiar), busca adequar \\
as plantas nativas de cada \\
região.
\end{tabular} \\
\hline
\end{tabular}


Quadro 1 - Padrões já utilizados pelo projeto Acolhida na Colônia.

Fonte: Modelo adaptado da tabela base - Dissertação de mestrado Moehlecke, 2010.

No Quadro 02 foram relacionados aqueles padrões recomendados, que ainda não fazem parte das estratégias da Associação e que podem ser inseridos nos planos diretores municipais.

QUADRO 2 - RECOMENDAÇÕES DE PADRÕES QUE PODEM SER INSERIDOS NAS ESTRATÉGIAS DO PROJETO

\begin{tabular}{|c|c|c|c|}
\hline \multicolumn{4}{|c|}{ LIMITE DE QUATRO ANDARES** (four-story limit) } \\
\hline $\begin{array}{l}\text { Problema/Contexto } \\
\text { (Padrão) }\end{array}$ & Recomendações & Relações & $\begin{array}{c}\text { Projeto Acolhida na } \\
\text { Colônia }\end{array}$ \\
\hline $\begin{array}{l}\text { Áreas centrais densas } \\
\text { devam ter restrições } \\
\text { quanto à altura das } \\
\text { edificações por não } \\
\text { representar vantagens } \\
\text { reais, exceto em ganhos } \\
\text { especulativos. } \\
\text { Ausência de } \\
\text { espaço abertos, } \\
\text { destruição da paisagem, } \\
\text { diminuição da } \\
\text { iluminação, ventilação. }\end{array}$ & $\begin{array}{c}\text { Edificações em torno } \\
\text { do limite de quatro } \\
\text { andares, mesmo em } \\
\text { zonas muito densas. }\end{array}$ & $\begin{array}{l}\text { Controle da altura das } \\
\text { edificações com vistas a } \\
\text { benefícios físico e mentais. } \\
\text { Equilíbrio da densificação } \\
\text { e a pressão ambiental. } \\
\text { A interação social e } \\
\text { participação comunitária, } \\
\text { para não interromper a } \\
\text { conexão do morador com } \\
\text { o cotidiano de seu lugar; } \\
\text { Habitabilidade, já que } \\
\text { a redução de altura } \\
\text { permite melhor insolação, } \\
\text { iluminação e ventilação. }\end{array}$ & $\begin{array}{l}\text { Respeito ao ambiente em } \\
\text { que estão inseridos. } \\
\text { Assessoria técnica para } \\
\text { as propriedades (unidade } \\
\text { familiar) rurais fazerem } \\
\text { adaptações em estruturas } \\
\text { existentes como galpões } \\
\text { de fumo, de máquinas } \\
\text { e transformam em } \\
\text { hospedagem. } \\
\text { As estruturas são simples e } \\
\text { rústicas, em sua maioria, e } \\
\text { estão localizadas na zona } \\
\text { rural. }\end{array}$ \\
\hline \multicolumn{4}{|c|}{ NÚCLEO EXCÊNTRICO* (eccentric nucleus) } \\
\hline $\begin{array}{l}\text { Problema/Contexto } \\
\text { (Padrão) }\end{array}$ & Recomendações & Relações & $\begin{array}{c}\text { Projeto Acolhida na } \\
\text { Colônia }\end{array}$ \\
\hline $\begin{array}{l}\text { O caráter aleatório } \\
\text { das densidades locais } \\
\text { confunde a identidade } \\
\text { das localidades e cria } \\
\text { o caos no uso do solo. } \\
\text { Explica que áreas de } \\
\text { alta densidade, capazes } \\
\text { de sustentar intensa } \\
\text { atividade, não podem } \\
\text { fazê-lo se estiverem } \\
\text { demasiadamente } \\
\text { dispersas. E áreas } \\
\text { capazes de oferecer } \\
\text { silêncio e tranquilidade, } \\
\text { não o são quando } \\
\text { estão demasiadamente } \\
\text { concentradas. }\end{array}$ & \begin{tabular}{|} 
Recomenda que \\
se estimule o \\
crescimento e \\
acumulação de \\
densidades, para \\
construir uma \\
configuração de \\
picos e vales, \\
definindo centros \\
de alta densidade, \\
limítrofes à \\
localidade, \\
prolongando a \\
alta densidade \\
na fronteira da \\
localidade, em forma \\
de ferradura.
\end{tabular} & $\begin{array}{l}\text { Este padrão está } \\
\text { relacionado a critérios } \\
\text { para a distribuição de } \\
\text { densidade. Valoriza altas } \\
\text { concentrações junto a } \\
\text { fronteiras, como forma de } \\
\text { delimitar localidades. A } \\
\text { distribuição de densidades } \\
\text { busca valorizar a intensa } \\
\text { atividade, mas também } \\
\text { valoriza áreas mais } \\
\text { dispersas, para descanso. } \\
\text { Equilíbrio da distribuição } \\
\text { de densidades. } \\
\text { Diversidade urbana, para } \\
\text { atender a diferentes } \\
\text { demandas. }\end{array}$ & $\begin{array}{l}\text { Preocupação com a cultura } \\
\text { local de forma a manter } \\
\text { suas características originais } \\
\text { Oferta de espaços para o } \\
\text { lazer e descanso para atrair } \\
\text { públicos de diversas idades }\end{array}$ \\
\hline \multicolumn{4}{|c|}{ ANÉIS DE DENSIDADE* (density rings) } \\
\hline $\begin{array}{l}\text { Problema/Contexto } \\
\text { (Padrão) }\end{array}$ & Recomendações & Relações & $\begin{array}{c}\text { Projeto Acolhida na } \\
\text { Colônia }\end{array}$ \\
\hline
\end{tabular}




\begin{tabular}{|c|c|c|c|}
\hline $\begin{array}{l}\text { As pessoas ora buscam, } \\
\text { diversão e serviços; } \\
\text { ora por tranquilidade. } \\
\text { Explica que o equilíbrio } \\
\text { entre estes desejos varia } \\
\text { entre as pessoas, mas } \\
\text { é esta dinâmica que } \\
\text { determina o gradiente } \\
\text { de densidade em um } \\
\text { bairro. Contudo, o custo } \\
\text { da terra varia conforme } \\
\text { a proximidade aos } \\
\text { centros de atividades, } \\
\text { proporcionando } \\
\text { desequilíbrio de } \\
\text { densidades. }\end{array}$ & $\begin{array}{c}\text { A partir de um } \\
\text { núcleo claramente } \\
\text { definido, que } \\
\text { se definam as } \\
\text { densidades dos } \\
\text { anéis, semicirculares, } \\
\text { decrescendo em } \\
\text { direção às bordas. }\end{array}$ & $\begin{array}{l}\text { Equilíbrio da distribuição } \\
\text { de pessoas pelo território. }\end{array}$ & $\begin{array}{l}\text { A construção do arranjo } \\
\text { institucional, formado } \\
\text { pelos municípios de Santa } \\
\text { Rosa de Lima, Anitápolis, } \\
\text { Rancho Queimado e } \\
\text { Urubici possibilitaram o } \\
\text { desenvolvimento territorial e } \\
\text { a permanência das famílias } \\
\text { em seus núcleos rurais, } \\
\text { com isso, surgem melhorias } \\
\text { nas vias de acesso, } \\
\text { sinalização, saneamento, } \\
\text { proporcionando, assim, o } \\
\text { equilíbrio das densidades } \\
\text { nos bairros. }\end{array}$ \\
\hline \multicolumn{4}{|c|}{ CASAS ALINHADAS* (row houses) } \\
\hline $\begin{array}{l}\text { Problema/Contexto } \\
\text { (Padrão) }\end{array}$ & Recomendações & Relações & $\begin{array}{c}\text { Projeto Acolhida na } \\
\text { Colônia }\end{array}$ \\
\hline $\begin{array}{l}\text { Casas contínuas são } \\
\text { importantes, quando há } \\
\text { alta densidade. Explica } \\
\text { que casas alinhadas } \\
\text { tradicionais (estreitas } \\
\text { e compridas) são mal } \\
\text { iluminadas, carecem } \\
\text { de privacidade. Este } \\
\text { padrão está relacionado } \\
\text { à necessidade de } \\
\text { equilibrar a ocupação } \\
\text { de alta densidade } \\
\text { e questões de } \\
\text { habitabilidade. Contribui } \\
\text { com estratégias que } \\
\text { permitem construir com } \\
\text { altas variações entre } \\
\text { casas. }\end{array}$ & $\begin{array}{l}\text { Que as casas sejam } \\
\text { alinhadas ao longo } \\
\text { de caminhos de } \\
\text { pedestres, com } \\
\text { fachadas largas e } \\
\text { pouco profundas, } \\
\text { compartilhando } \\
\text { pátios internos } \\
\text { à quadra, } \\
\text { perpendiculares } \\
\text { às vias principais, } \\
\text { onde se abastecem } \\
\text { infraestruturas. }\end{array}$ & $\begin{array}{l}\text { Pode contribuir para } \\
\text { ampliar a interação } \\
\text { entre vizinhos; para } \\
\text { maior habitabilidade do } \\
\text { conjunto edificado. }\end{array}$ & $\begin{array}{l}\text { As construções existentes } \\
\text { no projeto obedecem às } \\
\text { características no espaço } \\
\text { rural e não se observam } \\
\text { problemas em relação } \\
\text { à iluminação ou à falta } \\
\text { de privacidade. Busca-se } \\
\text { respeitar as características } \\
\text { da colonização e do } \\
\text { cotidiano agrícola, } \\
\text { sendo necessário um } \\
\text { acompanhamento técnico. } \\
\text { Nos núcleos urbanos este } \\
\text { tipo de padrão é bem } \\
\text { importante, porque favorece } \\
\text { as relações de vizinhança } \\
\text { e o padrão construtivo das } \\
\text { residências. }\end{array}$ \\
\hline \multicolumn{4}{|c|}{ CORREDORES ECOLÓGICOS } \\
\hline $\begin{array}{l}\text { Problema/Contexto } \\
\text { (Padrão) }\end{array}$ & Recomendações & Relações & $\begin{array}{l}\text { Projeto Acolhida na } \\
\text { Colônia }\end{array}$ \\
\hline $\begin{array}{l}\text { Há necessidade de } \\
\text { implementação de } \\
\text { maiores áreas de lazer } \\
\text { e ecológicas nas áreas } \\
\text { urbanas para que as } \\
\text { pessoas possam ter } \\
\text { acesso a este tipo de } \\
\text { equipamento. }\end{array}$ & $\begin{array}{c}\text { Implementar } \\
\text { corredores } \\
\text { ecológicos no meio } \\
\text { urbano e estimular o } \\
\text { acesso da localidade } \\
\text { através da criação } \\
\text { de parques e } \\
\text { praças urbanos, } \\
\text { principalmente em } \\
\text { áreas contíguas } \\
\text { as margens dos } \\
\text { rios que cortam as } \\
\text { cidades integrantes } \\
\text { do projeto. }\end{array}$ & $\begin{array}{c}\text { Parceria com os } \\
\text { municípios para garantir } \\
\text { a priorização e a } \\
\text { implementação deste tipo } \\
\text { de equipamento urbano. } \\
\text { A área rural e a urbana } \\
\text { devem estar associadas } \\
\text { ao projeto maior de } \\
\text { incrementar o turismo no } \\
\text { espaço rural. }\end{array}$ & $\begin{array}{l}\text { Os mutirões do plantio de } \\
\text { mudas e árvores nativas } \\
\text { visam melhorar o entorno } \\
\text { e a entrada de alguns } \\
\text { municípios pequenos. }\end{array}$ \\
\hline
\end{tabular}




\begin{tabular}{|c|c|c|c|}
\hline \multicolumn{4}{|c|}{ PRAÇAS E HORTAS COMUNITÁRIAS } \\
\hline $\begin{array}{l}\text { Problema/Contexto } \\
\text { (Padrão) }\end{array}$ & Recomendações & Relações & $\begin{array}{c}\text { Projeto Acolhida na } \\
\text { Colônia }\end{array}$ \\
\hline $\begin{array}{l}\text { Projetar rede de espaços } \\
\text { abertos (praças e hortas } \\
\text { comunitárias) separados } \\
\text { por uma distância de } \\
\text { até } 220 \text { metros, de } \\
\text { forma que possam ser } \\
\text { acessados, de qualquer } \\
\text { ponto da cidade, a partir } \\
\text { de uma caminhada } \\
\text { de até três minutos } \\
\text { (ALEXANDER, 1977). }\end{array}$ & \begin{tabular}{|c|} 
As novas praças \\
devem ter uma área \\
mínima de $5.000 \mathrm{~m}^{2}$ \\
e o comprimento \\
mais estreito, de \\
no mínimo $45 \mathrm{~m}$, \\
pois, segundo \\
Alexander (1977), \\
tais dimensões \\
são as mínimas \\
necessárias para que \\
uma pessoa se sinta \\
em contato com a \\
natureza e distante \\
da atribulação da \\
cidade.
\end{tabular} & $\begin{array}{l}\text { Previsão de espaços } \\
\text { para implantação } \\
\text { de equipamentos } \\
\text { comunitários devem ser } \\
\text { previstos na legislação } \\
\text { local. }\end{array}$ & $\begin{array}{l}\text { Produção orgânica para as } \\
\text { merendas escolares. }\end{array}$ \\
\hline \multicolumn{4}{|c|}{ PAISAGISMO PRODUTIVO } \\
\hline $\begin{array}{l}\text { Problema/Contexto } \\
\text { (Padrão) }\end{array}$ & Recomendações & Relações & $\begin{array}{c}\text { Projeto Acolhida na } \\
\text { Colônia }\end{array}$ \\
\hline $\begin{array}{l}\text { Propor paisagismo } \\
\text { produtivo (hortas e } \\
\text { pomares) no entorno } \\
\text { das áreas construídas; }\end{array}$ & $\begin{array}{c}\text { Implantar pequenos } \\
\text { pomares de árvores } \\
\text { frutíferas, em jardins } \\
\text { e em espaços } \\
\text { públicos ao longo de } \\
\text { caminhos e ruas, nos } \\
\text { parques, nos bairros } \\
\text { onde existem grupos } \\
\text { bem estabelecidos } \\
\text { que podem cuidar } \\
\text { por si próprios, das } \\
\text { árvores e da colheita } \\
\text { dos frutos. }\end{array}$ & \begin{tabular}{|} 
Espécies de acordo \\
com a natureza local, \\
a fim de conformar \\
lugares utilizáveis para a \\
localidade nas praças, nos \\
recantos, e nas ruas.
\end{tabular} & $\begin{array}{l}\text { O poder público deverá } \\
\text { incentivar, dando o exemplo } \\
\text { em áreas públicas e, além } \\
\text { disto, dar incentivos através } \\
\text { de benefícios fiscais às } \\
\text { populações urbanas que } \\
\text { adotarem este tipo de ação. }\end{array}$ \\
\hline \multicolumn{4}{|c|}{ INTEGRAÇAO DAS AGUAS } \\
\hline $\begin{array}{l}\text { Problema/Contexto } \\
\text { (Padrão) }\end{array}$ & Recomendações & Relações & $\begin{array}{c}\text { Projeto Acolhida na } \\
\text { Colônia }\end{array}$ \\
\hline $\begin{array}{l}\text { Em função das inúmeras } \\
\text { ocorrências em vários } \\
\text { municípios catarinenses } \\
\text { com enxurradas, é } \\
\text { importante se promover } \\
\text { o ciclo natural de } \\
\text { integração das águas } \\
\text { pelo território. }\end{array}$ & $\begin{array}{c}\text { Conforme padrão } \\
64 \text { proposto por } \\
\text { Alexander (1977), } \\
\text { as estradas, } \\
\text { quando existirem, } \\
\text { devem estar } \\
\text { perpendiculares ao } \\
\text { rio e aos córregos da } \\
\text { região. }\end{array}$ & $\begin{array}{c}\text { Equilíbrio das águas com a } \\
\text { malha viária no território. }\end{array}$ & $\begin{array}{l}\text { O poder público deverá } \\
\text { rever e adequar a malha } \\
\text { viária para que se possa } \\
\text { efetivamente promover a } \\
\text { integração das águas por } \\
\text { todo território municipal. }\end{array}$ \\
\hline
\end{tabular}

Quadro 2 - Recomendações de padrões que podem ser inseridos nas estratégias do projeto.

Fonte: Modelo adaptado da tabela base - Dissertação de mestrado de Moehlecke, 2010. 
Nesta pesquisa, foram descritos os padrões adotados Christopher Alexander, de maior relevância e com base na realidade do território que compõe a Associação AAAC. Esses padrões podem ser incrementados e têm como orientação a utilização racional dos recursos naturais, a utilização crescente de recursos renováveis, limitando a utilização dos não renováveis, respeitando a capacidade de carga dos ecossistemas e minimizando impactos ambientais. Os padrões relativos à biodiversidade têm sido prioritários no projeto Acolhida na Colônia, especialmente o respeito e a preservação de áreas naturais e a valorização das características locais. Ao longo da análise, baseada em informações em campo e dos quadros 01 e 02, foi possível observar alguns aspectos positivos, como:

a) O uso de estratégias vinculadas a um Caderno de Normas;

b) Preocupação com a melhoria do meio ambiente e a biodiversidade no território;

c) Incentivo ao associativismo e à inserção de agroindústrias;

d) Melhoria no paisagismo e na diversificação da produção, produtos e serviços;

e) Melhoria na qualidade das famílias agrícolas.

Importante salientar os padrões relacionados à economia local, já que o projeto Acolhida na Colônia está sustentado nos princípios de geração de emprego e renda no meio rural. A diversificação da produção agrícola, o cultivo orgânico, a capacitação dos produtores locais para o uso de técnicas de permaculturas e a produção orgânica têm sido o foco principal do projeto Acolhida na Colônia. Por esse motivo, sua relação com os padrões adotados por Christopher Alexander, considerados uma referência em relação à análise do ambiente físico e qualidade espacial dos lugares, é uma alternativa para incrementar ainda mais as estratégias adotadas pelo projeto.

Ainda, ao longo da análise, também foram observadas algumas limitações dentro do projeto $A A A C$, tais como:

a) A necessidade de melhoria na comercialização e na divulgação, uma vez que se trata de um produto turístico para um público específico de pessoas que buscam um contato com o meio ambiente e a valorização do campo; 
b) A falta de fiscalização dos empreendimentos irregulares nos municípios, ocasionado uma disputa desleal com os autóctones, que são predominantemente agricultores familiares. Este fato leva à "desocupação" do campo pelos agricultores familiares e, apesar dos investimentos demandarem um maior número de serviços públicos, por estarem no meio rural, não contribui com pagamentos significativos de tributos.

\section{CONSIDERAÇÕES FINAIS}

O estudo permitiu um conhecimento acerca dos instrumentos de análise da temática da sustentabilidade, necessários para indicar melhorias de uma proposta com perspectivas de integração regional. Neste sentido, essa ferramenta de análise, baseada nos padrões de Christopher Alexander, busca opções que asseguram a reprodução da Associação Acolhida na Colônia pertinentes, em função de um processo de desenvolvimento com enfoque territorial.

No caso em estudo, o agroturismo, presente como atividade principal na Associação Acolhida na Colônia, aparece como uma nova oportunidade de trabalho para estes agricultores, por meio da prestação de serviços de hospedagem, alimentação ou lazer, ou fora das unidades familiares, em atividades ligadas diretamente ao turismo, como guia ou condutor. O turismo no espaço rural deve ser visto como uma fonte de renda complementar para as famílias do meio rural, desde que as mesmas não percam sua originalidade e preservem seu patrimônio cultural, buscando a melhoria nas condições de vida no campo.

Neste sentido os padrões de Alexander et al. (1977), aqui estudados, poderão acrescentar e potencializar resultados ainda mais atrativos aos visitantes e às pessoas que residem na região. Os padrões urbanos associados a medidas no meio rural, que já tem sido utilizado pelo Projeto Acolhida na Colônia, podem contribuir para assentamentos mais sustentáveis. Essa visão só foi possível a partir das análises que identificaram algumas limitações observadas no território da Associação, em relação aos padrões já utilizados, possibilitando ainda propor recomendações por meio de novos padrões, a partir da sua inserção nos planos 
diretores municipais, em que muitas famílias de agricultores poderão melhorar a qualidade de vida.

Contudo, a pesquisa apresenta algumas limitações em função de o tema ser incipiente de produção científica a respeito, especialmente quando adaptado ao espaço rural.

Assim, se faz imprescindível que esses padrões sejam mais bem estudados para sua adoção e o exercício na utilização de alguns destes, visando ao incremento do projeto Acolhida na Colônia por meio de princípios de sustentabilidade e de geração de emprego e renda, aprimorando as potencialidades e o saber local. Poderão contribuir sobremaneira para o sucesso do projeto de forma integrada regionalmente, tendo o agroturismo como matriz de inserção social e econômica da população.

Os padrões de Alexander são uma ferramenta importante para implementação de princípios de sustentabilidade no contexto urbano e rural. A inter-relação de princípios e a adoção de uma visão estratégica de intervenção integrada regionalmente, de forma sistêmica e holística, podem favorecer ainda mais o projeto Acolhida na Colônia, aqui estudado, para que se torne ainda mais um referencial em Santa Catarina e no Brasil.

A partir dessa análise, foram propostas algumas recomendações que poderão ser inseridas nos planos diretores municipais:

a) Fiscalização e assessoria nas estruturas existentes e ocupação dos núcleos urbanos e rurais para que ocorra uma padronização nas construções;

b) Manutenção da cultura local para que não ocorram a descaracterização e a dinamização dos espaços de lazer;

c) Incentivo à diversificação nas hortas, pomares e paisagismo, dinamizando as atividades na propriedade (unidade familiar) e auxiliando nas merendas escolares;

d) Ampliação dos arranjos institucionais para fortalecer a Associação e promoção da integração entre rural e urbano; 
e) Adequação da malha viária, visando à preservação das águas.

Observou-se também que, apesar de não se ter identificados padrões relacionados diretamente ao desenvolvimento do turismo, certamente o mesmo ocorrerá em função de princípios adotados e tornarão as cidades e as áreas rurais atrativas para os visitantes.

\section{REFERÊNCIAS BIBLIOGRÁFICAS}

ASSOCIAÇÃO DE AGROTURISMO ACOLHIDA NA COLÔNIA (AAAC). Disponível em: <www. acolhida.com.br>. Acesso em: 28 de fev. de 2013.

ALEXANDER, C.; ISHIKAWA, S.; SILVERSTEIN, M. A pattern Language. Oxford University Press: New York, 1977.

BARQUERO, A. V. Desenvolvimento endógeno em tempos de globalização. Porto Alegre: FEE/UFRGS, 2002.

BRASIL, Ministério do Turismo. Diretrizes para o Desenvolvimento do Turismo Rural no Brasil. Brasília, 2011.

BECKER, D. F. Desenvolvimento local-regional: determinantes e desafios contemporâneos. Santa Cruz do Sul, Editora Unisc, 2000a.

BOISIER, S. Planejamento de Políticas Públicas. Em busca do esquivo desenvolvimento regional: entre a caixa-preta e o projeto político. N 13. Santiago do Chile: ILPES. 1996.

BOULLÓN, R. C. Planejamento do espaço turístico. Tradução de Josely Vianna Baptista. Bauru, SP: EDUSC, 2002.

CABRAL, L. O. Espaço e ruralidade num contexto de desenvolvimento voltado à agricultura familiar. Florianópolis, 2004.Tese (Doutorado), Programa de Pós-Graduação em Geografia. Universidade Federal de Santa Catarina.

CARNEIRO, M. J. Multifuncionalidade da agricultura e ruralidade: uma bordagem comparativa. In: Org. Roberto José Moreira, Luiz F. de Carvalho Costa. Mundo Rural e cultura. Rio de Janeiro: MAUAD, 2002. p. 65-102.

CMMAD - Comissão Mundial sobre Meio Ambiente e Desenvolvimento. Nosso Futuro Comum. Rio de Janeiro: Editora da Fundação Getúlio Vargas, 1988.

CORIOLANO, L. N. M. T. Arranjos produtivos locais do turismo comunitário: atores e cenários em mudança. Fortaleza: EdUECE, 2009. 
DIAS, R. Planejamento turístico: política e desenvolvimento do turismo no Brasil. São Paulo: Atlas S.A, 2003.

GOMEZ-LIMON, J. A. Measuring Individual Preferences for Rural Multifunctionality: The Importance of Demographic and Residential Heterogeneity. Journal of Agricultural Economics, Vol. 63, no. 1, 2012. p. 1-24.

GUZZATTI, T. $\mathbf{O}$ agroturismo como elemento dinamizador na construção de territórios rurais: $O$ caso da Associação de Agroturismo Acolhida na Colônia em Santa Rosa de Lima (SC). Florianópolis, 2010. Tese doutorado em geografia, Universidade Federal de Santa Catarina.

JORDAN, A. G. Considerações sobre o Desenvolvimento Territorial. Notas de Aula, Projeto Meu Lugar, Fpolis, 2004.

LYNCH, K. A boa forma da cidade. Edições 70, LDA, 2007.

MINISTÉRIO DO DESENVOLVIMENTO AGRÁRIO (MDA). Desenvolvimento agrário como estratégia: balanço MDA, 2003-2006. Porto Alegre: Nead, 2006.

MOEHLECKE, J. Uma contribuição para o desenvolvimento de assentamentos humanos mais sustentáveis: Identificação de padrões urbanos relacionados aos princípios de sustentabilidade. Porto Alegre, PPGEC/UFRGS, 2010.

MINISTÉRIO DO DESENVOLVIMENTO AGRÁRIO (MDA). Desenvolvimento agrário como estratégia: balanço MDA, 2003-2006. Porto Alegre: Nead, 2006.

MINISTÉRIO DO TURISMO (MTUR). Diretrizes para o desenvolvimento do turismo rural no Brasil, 2007-2010. Disponível em: <www.pronaf.gov.br/turismo/programadeturismorural. pdt $>$. Acesso em: 18 de Abril de 2011.

ORGANIZAÇÃO MUNDIAL DO TURISMO (OMT). Guia de desenvolvimento sustentável. Porto Alegre: Bookman, 2003.

SCHMIDT, W.; SCHMIDT, W. e TURNES, V. A. Desenvolvimento local em espaços rurais; a construção de um "território" nas Encostas da Serra Geral, em SC. In: PAULILO, M. I. e SCHMIDT, W. (Orgs.). Agricultura e espaço rural em Santa Catarina. Florianópolis: Ed. UFSC, 2003.

RODRIGUES, A. M. Desenvolvimento Sustentável e atividade Turística. In: RODRIGUES, Adyr B. Turismo: Desenvolvimento Local. São Paulo, Hictec, 2002.

SACHS, I. Estratégias de transição para o século XXI - desenvolvimento e meio ambiente. São Paulo: Studio Nobel/Fundap, 1993. 
Caminhos para o desenvolvimento sustentável. Rio de Janeiro: Garamond, 2002.

SANTOS, M. A natureza do espaço. 4. ed. São Paulo: EDUSP, 2004.

SATTLER, M. A. Habitações de Baixo Custo mais Sustentáveis: a Casa Alvorada e o Centro Experimental de Tecnologias Habitacionais Sustentáveis. Coleção Habitare, v.8. Porto Alegre: ANTAC, 2007.

SILVA, J. G. da. Velhos e novos mitos do rural brasileiro, 2001. Disponível em: <www.rcl. fao.org >. Acesso em 15 de setembro de 2011.

SCHNEIDER, S. A pluriatividade na agricultura familiar. Porto Alegre: Ed. da UFRGS, 2003.

TURNES, V.; ROSA, S. L. C.; TEIXEIRA, J. P.; REBESCHINI, P. R.; JORDAN, A. G.; PIRES, A.; DAMO, M. S. Projeto Meu Lugar. Transformar regiões administrativas em territórios de desenvolvimento. Florianópolis: Cidade Futura, 2004. 184p.

\section{CONTRIBUIÇÃO DOS AUTORES NA CONSTRUÇÃO DO ARTIGO}

WAKOWSKI: Introdução, Referencial teórico e análise de dados.

DAMO: Introdução, Referencial teórico e análise de dados.

LOCH: Considerações finais e revisão. 